\title{
O come, all ye faithful: a study on church syncope
}

Biswadev Mitra MB BS, PhD, FACEM Emergency Physician

Andrew J Tagg BSc, MB BS, MRCS, Registrar in Emergency Medicine

Elyse Fyfe Medical Student

Gerard M O'Reilly MB BS, FACEM, ASTAT Senior Research Fellow, Department of Epidemiology and Preventive Medicine

1 Emergency and Trauma Centre, The Alfred Hospital, Melbourne, VIC.

2 Monash University, Melbourne, VIC

b.mitra@alfred.org.au

MJA 2013; 199: 807-809 doi: 10.5694/mjal3.11314
... willing rather to be absent from the body, and to be present with the Lord (2 Cor 5:8)

ince historical times, fainting in church has been anecdotally common. Up to $40 \%$ of calls to emergency medical services on a Sunday morning may be associated with "church syncope". ${ }^{1}$ Church syncope is often listed as a subtype of syncope among medical presentations, yet apart from circumstantial cases ${ }^{2}$ and one case report of syncope in the church choir, ${ }^{3}$ the epidemiology of church syncope has not been reported in the medical literature.

The church is considered a sacred place, with sanctity sometimes derived from the location where it is built - where a miracle or martyrdom allegedly took place or a holy person was buried, or by the location of a holy item placed within the church. Associated with this sanctity is the concept of sanctuary from intentional physical harm (eg, fugitives were immune to arrest in a church under English law from the fourth to the 17th century). Along the same lines, improved health outcomes and wellbeing from spirituality and the sanctity of the church have also been reported. $^{4,5}$

Our aim was to investigate the incidence of patients presenting to a major metropolitan hospital after experiencing church syncope. A further aim was to determine whether syncope in this sacred location is associated with improved outcomes. We hypothesised that patients presenting to the emergency department (ED) with church syncope would have similar short-term (at hospital discharge) outcomes as those presenting with syncope experienced at other locations (ie, that the sanctity of the church is associated with no additional sanctuary).

\section{Abstract}

Objectives: To determine the incidence of patients presenting to a major metropolitan hospital after experiencing syncope at church, and to compare their outcomes with those of patients experiencing syncope at other locations.

Design, setting and participants: A retrospective matched cohort study in which patients presenting with church syncope between July 2009 and June 2013 were compared with controls (patients presenting after syncope experienced elsewhere) matched by 5-year age group and San Francisco Syncope Score.

Main outcome measures: Admission to hospital was the primary outcome measure. Mortality, intensive care unit or coronary care unit admission, and length of stay in hospital were secondary outcome measures.

Results: There were 31 cases of church syncope during the study period, which were matched to 62 controls. The hospital admission rate among patients who experienced syncope in church was significantly lower than among controls (22.6\% v 46.8\%; $P=0.02$ ). After adjusting for other variables significantly associated with admission to hospital, the church as a location for syncope was no longer significantly associated with hospital admission (odds ratio, 0.4; 95\% Cl, 0.1-1.1; $P=0.06$ ).

Conclusions: The number of patients presenting to hospital after church syncope was low; most had benign diagnoses and were discharged home from the emergency department. While syncope at church was associated with a lower rate of hospital admission, the church did not appear to offer any additional sanctuary when clinical risk profiles were taken into consideration.

\section{Methods}

We conducted a retrospective matched cohort study at the Alfred Hospital, an adult major referral hospital in central Melbourne, Victoria. The hospital receives over 50000 emergency presentations each year. There are 73 churches within the central business district of Melbourne and surrounding $5 \mathrm{~km}$ radius. Approval was obtained for this study from the Alfred Hospital Research and Ethics Committee.

We searched the Emergency and Trauma Centre database for presentations during a 4-year period from July 2009 to June 2013. Medical records were extracted for all presentations with the word "church" documented in the ambulance description, description of triage, place of incident, or discharge description. Two investigators (A J T and E F) independently reviewed medical records through an explicit chart review. Patients with church syncope were identified as cases, and data on demographic and clinical characteristics, management and hospital outcomes were extracted.

Patients who presented to the ED during the same period with "syncope", "collapse" or "faint" were identified as possible controls. Cases were matched to controls by age (corrected to the nearest 5-year age group) and San Francisco Syncope

\footnotetext{
1 San Francisco Syncope Score ${ }^{6}$ Indication

- Syncope evaluation

Evaluate short-term risk of serious outcome

May reduce syncope hospitalisation rate

Criteria

- History of congestive heart failure

- Haematocrit level < $30 \%$

- Abnormal electrocardiogram

- History of shortness of breath

- Systolic blood pressure $<90 \mathrm{mmHg}$ at triage

Interpretation

- Positive with any one of the above criteria
} 
Score (SFSS). ${ }^{6}$ The SFSS (Box 1) was developed to identify patients at risk of serious outcomes (death, myocardial infarction, arrhythmia, pulmonary embolism, stroke, subarachnoid haemorrhage, significant haemorrhage or any condition causing a return ED visit and hospitalisation for a related event) within 30 days of presentation. To minimise bias due to seasonal variance, control patients for cases were selected as the next chronologically presenting patients who matched selection criteria.

\section{Statistical analysis}

Admission to hospital was the primary outcome measure. The prevalence of the primary outcome among the control group was estimated to be 0.50 . With a chosen power of 0.8 , $\alpha$ of 0.05 , correlation coefficient for outcome between cases and matched controls (phi) of 0.2 , and odds ratio of 3.0, the optimal number of controls was determined to be two per case. ${ }^{7}$ Mortality at hospital discharge, intensive care or coronary care unit admission, and length of stay in hospital were secondary outcome measures.

Normally distributed continuous variables are reported as means with standard deviations, and ordinal or skewed variables are reported as medians with interquartile ranges (IQRs). The association between categorical variables is described using odds ratios (ORs) with 95\% confidence intervals. We calculated the statistical significance of odds ratios using the Mantel-Haenszel method for matched data. Variables showing an association with admission to hospital $(P<0.1)$ were entered into a conditional logistic regression model to determine independent associations with admission to hospital. Statistical significance was defined as $P<0.05$.

\section{Results}

During the study period, 46 patients presented to the ED after an incident related to a church. After review, 15 of these were excluded: seven patients presented after a fall in church or church grounds without syncope, three patients experienced symptoms (chest pain and nausea) in church

\section{Demographic and clinical characteristics of patients*}

\begin{tabular}{lcc} 
& $\begin{array}{c}\text { Church syncope } \\
(n=31)\end{array}$ & $\begin{array}{c}\text { Other syncope } \\
(n=62)\end{array}$ \\
\hline Age (years), ${ }^{\dagger}$ mean (SD) & $79.3(6.8)$ & $79.7(6.7)$ \\
Male & $9(29.0 \%)$ & $15(24.2 \%)$ \\
Religion & $5(16.1 \%)$ & $7(11.3 \%)$ \\
Anglican & $7(22.6 \%)$ & $5(8.1 \%)$ \\
Greek Orthodox & $8(25.8 \%)$ & $10(16.1 \%)$ \\
Roman Catholic & $3(9.7 \%)$ & $9(14.5 \%)$ \\
Uniting & $3(9.7 \%)$ & $10(16.1 \%)$ \\
Other & $5(16.1 \%)$ & $21(33.9 \%)$ \\
Not specified & $3(9.7 \%)$ & $7(11.3 \%)$ \\
History of congestive heart failure & $37 \%(4 \%)$ & $36 \%(5 \%)$ \\
Haematocrit level, mean (SD) & $16(51.6 \%)$ & $39(62.9 \%)$ \\
Abnormal electrocardiogram & $5(16.1 \%)$ & $9(14.5 \%)$ \\
History of shortness of breath & $129.9(18.5)$ & $140.6(26.8)$ \\
Systolic blood pressure (mmHg), mean (SD) & $0(0-1)$ \\
San Francisco Syncope Score, median (IQR) ${ }^{\dagger}$ & $0(0-1)$ & $36.3(0.5)$ \\
Temperature $\left({ }^{\circ} \mathrm{C}\right)$, mean (SD) & $36.2(0.3)$ & $12(19.4 \%)$ \\
Absence of symptoms preceding syncope & $3(9.7 \%)$ & $10(16.1 \%)$ \\
Diabetes mellitus & $3(9.7 \%)$ & $12(19.4 \%)$ \\
Trauma resulting from syncope & 0 & \\
\hline
\end{tabular}

* Figures are number (\%) of patients unless otherwise specified. $\uparrow$ Matched variables.

without syncope, two patients presented after episodes of self-harm in church, two patients developed back pain while sitting on church benches, and (as the search term also matched partial words), one patient was a visitor, without syncope, from Christchurch, New Zealand. This left 31 patients in the study, who were compared with 62 control patients. Demographic and presenting clinical features of patients are shown in Box 2. The mean age of patients was 79.3 years in the case group and 79.7 years in the control group, and the median SFSS for each group was 0 (IQR, 0 1), demonstrating successful matching. Discharge diagnoses of patients presenting with church syncope are shown in Box 3.

Seven patients with church syncope (22.6\%) were admitted to hospital, a significantly lower proportion than among control patients (29; 46.8\%) (Mantel-Haenszel analysis for matched pairs, $P=0.02$ ). Results of the testing for a univariate association of demographic and clinical variables with admission to hospital are listed in Box 4. After multivariable analysis using conditional logistic regression, there was no statistically significant independent association of church as the location for syncope with admis-
3 Discharge diagnoses of patients presenting with church syncope

\begin{tabular}{lc} 
Diagnosis & $\begin{array}{c}\text { Patients } \\
(n=31)\end{array}$ \\
\hline Vasovagal syncope & 14 \\
No specific diagnosis & 5 \\
Acute coronary syndrome & 3 \\
Arrhythmia & 3 \\
Dehydration & 2 \\
Benign positional vertigo & 1 \\
Bradycardia secondary to & 1 \\
medication & \\
Urinary tract infection & 1 \\
Autonomic instability & 1
\end{tabular}

sion to hospital (OR, 0.4; 95\% CI, $0.1-$ 1.1; $P=0.06)$. Systolic blood pressure on presentation to the ED was the only included variable to have a statistically significant association with admission to hospital (OR, 1.0; 95\% CI, 1.0-1.1).

There were no deaths in either group. Four patients with church syncope $(12.9 \%)$ and seven control patients $(11.3 \%)$ were admitted to an intensive care or coronary care unit (Mantel-Haenszel analysis for matched pairs, $P=0.8$ ). Among admitted patients, the median length of stay for both groups was 1 day (IQR, 1-2 days). Two patients with church syncope underwent insertion 
of a permanent pacemaker, whereas five patients in the control group underwent other surgical procedures.

\section{Discussion}

This study, the first to analyse shortterm outcomes of patients with church syncope, found that the incidence of patients presenting to hospital with church syncope was substantially lower than has been anecdotally reported. When compared with patients with similar risk profiles experiencing syncope at locations other than a church, a significantly lower proportion of patients with church syncope were admitted to hospital. However, after adjusting for age, SFSS, presence of diabetes mellitus, abnormality on electrocardiogram and presenting systolic blood pressure, church as a location for syncope was not significantly associated with admission to hospital. The sanctity of a church to provide sanctuary against hospital admission after syncope therefore remains unproven.

The patients with church syncope had better outcomes than those previously reported for patients presenting to the ED with syncope (occurring in any location). Reported adverse event rates for patients presenting with syncope range from $6.1 \%$ to $11.5 \%$, 6,8 with short-term mortality rates of 1.5 to $1.9 \% .^{9-11}$ Rather than divine influence, the better outcomes seen in patients experiencing syncope at church were most likely related to selection bias of a relatively less unwell group of patients. Factors that are likely to be associated with syncope in church include prolonged morning activities while fasting; being stationary in an often warm, enclosed and crowded environment with limited ventilation; or being emotionally charged in the setting of prayers - all of which are more likely to be associated with benign medical conditions.

Beneficial effects of the church on health outcomes may also be gleaned from studies that have correlated church attendance with posi- tive health care practices. Health benefits of church attendance have been reported to include improved rates of mammography, blood pressure measurements and dental visits, and improved social integration and attendance at cancer prevention services. ${ }^{11-14}$ However, these claims, although multiple, have been refuted in systematic reviews of the literature. $^{15}$

Although this study found no significant association between church as a location and short-term outcomes among patients with syncope, multiple limitations must be acknowledged. Although this is the largest reported case series on the topic that we are aware of, it was a retrospective review involving a relatively small number of patients. The inclusion criteria were based on history recorded by prehospital and triage staff, and patients with variants of syncope, such as presyncope, vertigo and dizziness, may have been included. The structured data form used in the explicit chart review did not include information on many variables that may be important in the evaluation of syncope, such as medication use, routine blood testing, orthostatic vital signs and carotid massage. The validity of the SFSS in determining risk for adverse events has been previously questioned ${ }^{9}$ and may have led to disproportionate matching of patients. Assessment and management of patients were considered to be of uniform level, with no adjustment made for seniority of attending clinicians.

In conclusion, the incidence of patients with church syncope presenting to the ED was low. Outcomes were generally favourable, but the church did not appear to offer any additional sanctuary when clinical risk profiles were considered.

\section{Competing interests: No relevant disclosures.}

Received 14 Oct 2013, accepted 25 Nov 2013.

$$
\begin{aligned}
& 1 \text { Sunday morning church service syncope. } \\
& \text { Paramedic Journal: A Year on the Streets 2006; } 15 \\
& \text { Jan. http://medic471.blogspot.com.au/2006/01/ } \\
& \text { sunday-morning-church-service-syncope.html }
\end{aligned}
$$
(accessed Sep 2013).
4 Unadjusted odds ratios for admission to hospital

\begin{tabular}{lc} 
Variable & Odds ratio $(95 \% \mathrm{Cl})$ \\
\hline Male & $0.7(0.2-2.9)$ \\
Haematocrit & $0.3\left(0.0-8.0 \times 10^{4}\right)$ \\
History of congestive heart failure & $0.8(0.1-4.2)$ \\
Abnormal electrocardiogram & $1.5(0.4-5.2)$ \\
History of shortness of breath & $0.8(0.2-3.6)$ \\
Systolic blood pressure* & $1.0(1.0-1.1)$ \\
Temperature & $0.4(0.1-1.4)$ \\
Absence of symptoms preceding syncope & $1.4(0.3-6.0)$ \\
Diabetes mellitus* & $4.0(0.8-20.9)$ \\
Trauma resulting from syncope & $1.0(0.3-4.3)$ \\
\hline
\end{tabular}

* Variables entered into the multivariable regression model, along with church as the location for syncope.

2 Zysko D, Gajek J, Smereka J, et al. ST-elevation in patient with vasovagal syncope. Folia Cardiol 2006; 13: 530-533.

3 Thomas AL, Fleet WF 3rd, Morgan HJ. A case of syncope in the church choir. J Tenn Med Assoc 1990; 83: 23

4 PuchalskiC. Spirituality in health: the role of spirituality in critical care. Crit Care Clin 2004; 20 : 487-504.

5 Como JM. Spiritual practice: a literature review related to spiritual health and health outcomes. Holist Nurs Pract 2007; 21: 224-236.

6 Quinn J, McDermott D, Stiell I, et al. Prospective validation of the San Francisco Syncope Rule to predict patients with serious outcomes. Ann Emerg Med 2006; 47: 448-454.

7 Hennessy S, Bilker WB, Berlin JA, Strom BL. Factors influencing the optimal control-to-case ratio in matched case-control studies. Am J Epidemiol 1999; 149: 195-197.

8 Costantino G, Perego F, Dipaola F, et al. Shortand long-term prognosis of syncope, risk factors, and role of hospital admission: results from the STePS (Short-Term Prognosis of Syncope) study. J Am Coll Cardiol 2008; 51: 276-283.

9 Sun BC, Mangione CM, Merchant G, et al. External validation of the San Francisco Syncope Rule. Ann Emerg Med 2007; 49: 420-427.e4.

10 Shiyovich A, Munchak I, Zelingher J, et al. Admission for syncope: evaluation, cost and prognosis according to etiology. Isr Med Assoc J 2008; 10: 104-108.

11 Levin JS, Chatters LM. Religion, health, and psychological well-being in older adults: findings from three national surveys. J Aging Health 1998; 10: 504-531.

12 Strawbridge WJ, Cohen RD, Shema SJ. Comparative strength of association between religious attendance and survival. Int J Psychiatry Med 2000; 30: 299-308.

13 Levin JS, Chatters LM, Taylor RJ. Religious effects on health status and life satisfaction among black Americans. J Gerontol B Psychol Sci Soc Sci 1995; 50B: S154-S163.

14 Felix Aaron K, Levine D, Burstin HR. African American church participation and health care practices. J Gen Intern Med 2003; 18: 908-913.

15 Sloan RP, Bagiella E. Claims about religious involvement and health outcomes. Ann Behav Med 2002; 24: 14-21. 